\title{
Travessias pela palavra em Exercicios de ser criança, de Manoel de Barros e em A maior flor do mundo, de José Saramago.
}

Joseane Maia Santos Silva ${ }^{1}$

RESUMO: O escritor pode contribuir para o fortalecimento da cultura de seu país através do exercício da palavra - matéria-prima da criação literária. Este é o compromisso assumido por Manoel de Barros e José Saramago em duas obras aqui analisadas na perspectiva dos estudos comparados.

ABSTRACT: The writer may contribute for the enrichment of his country's culture, throughout the word practicing - raw material of literacy creation. This is assumed by Manoel de Barros and José Saramago in both works, analyzed in this article from the perspective of comparing studies.

PALAVRAS-CHAVE: Manoel de Barros; José Saramago; escritor; palavra; criação literária.

KEY-WORDS: Manoel de Barros; José Saramago; writer; word; literacy creation.

Escrever, essa foi a única coisa que habitou minha vida e que a encantou. Eu o fiz. A escrita não me abandonou nunca ${ }^{2}$.

A citação de Marguerite Duras como testemunho pessoal sobre o exercício da escrita abre possibilidades para reflexões sobre a linguagem, isto é, sobre a criação literária, bem como sobre o papel do escritor enquanto porta-voz da cultura de seu país.

A literatura enquanto arte revela nas coisas vistas ou sabidas múltiplas visões do mundo, como resultado das estratégias discursivas utilizadas pelo escritor, possibilitando uma experiência estética, através da prática da leitura. É nessa medida que pode representar uma função

\footnotetext{
1 Professora do Centro de Estudos Superiores de Caxias-Universidade Estadual do Maranhão e doutoranda em Estudos Comparados de Literaturas de Língua Portuguesa, FFLCH-USP. Pesquisa: Tecendo estórias das comunidades negras rurais quilombolas aqui e acolá (título provisório).

E-mail:joseanemssilva@yahoo.com.br.

2 DURAS, Marguerite. Escrever. Tradução de Rubens Figueiredo, Rio de Janeiro, Rocco, 1994.
} 
ética a exemplo do papel do intelectual na concepção de Said que, de acordo com suas palavras, não pode ser reduzido a um profissional sem rosto para "ser um indivíduo dotado de uma vocação para representar, dar corpo e articular uma mensagem, um ponto de vista, uma atitude, filosofia ou opinião para (e também por) um público"3.

Assim sendo, analisando o trabalho com a linguagem realizado por Manoel de Barros e José Saramago, nas obras Exercícios de ser Criança ${ }^{4}$ e $A$ maior flor do mundo ${ }^{5}$, verifica-se que ambos empreendem uma reflexão metatextual, explorando o percurso da palavra em sua capacidade de "dizer o indizivel", como afirma Eduardo Lourenço que caracteriza a literatura como uma máquina retórica singular, fonte de emoção e êxtase. ${ }^{6}$

Ilustrado pela família Diniz Dumont, num trabalho inovador, com desenhos bordados, realçando a força imagética das palavras, o livro Exercícios de ser criança, em prosa poética, enreda o leitor em duas estórias - O menino que carregava água na peneira e A menina avoadaque relacionam o fazer poético com a infância - etapa em que o conhecimento da realidade efetiva-se pelo sensível, pelo emotivo e pela intuição, com predomínio do pensamento mágico, razão por que é considerada fase decisiva, para a formação do futuro leitor, a interação com obras literárias cujas temáticas abordem questões de seus interesses e necessidades.

$\mathrm{Na}$ primeira narrativa, um menino "que carregava água na peneira” dialoga com a mãe que compara essa ação com o mesmo que "roubar um vento e sair correndo com ele para mostrar aos irmãos", "o mesmo que catar espinhos na água", "o mesmo que criar peixes no bolso", em resumo, se para o narrador, “o menino era ligado em

3 SAID, Edward W. Representações do intelectual: As Conferências Reith de 1993. Tradução de Milton Hatoum, São Paulo, Companhia das Letras, s.d.

4 BARROS, Manoel de. Exercícios de ser Criança. Bordados de Antônia Zulma et. Alli sobre desenhos de Demóstenes Vargas. Rio de Janeiro, Salamandra, 1999.

5 SARAMAGO, José. A maior flor do mundo. Ilustrações de João Caetano. São Paulo, Companhia das Letrinhas, 2001.

${ }^{6}$ LOURENÇO, Eduardo. "Da Filosofia como Literatura". IN: Estudos universitários de língua e literatura. Textos de vários autores. Rio de Janeiro, Editora Tempo Brasileiro, 1993. 
despropósito", para a personagem/mãe cabe o vaticínio: "meu filho você vai ser poeta. Você vai carregar água na peneira a vida toda”. Assim, aquele menino "cismado e esquisito", "quis montar os alicerces de uma casa sobre orvalhos", "gostava mais do vazio do que do cheio", "falava que os vazios são maiores e até infinitos", "foi capaz de modificar uma tarde botando uma chuva nela", "até fez uma pedra dar flor!" e descobriu que escrever era tudo isso, e mais: era "fazer peraltagens com as palavras".

Na segunda narrativa, uma menina, juntamente com o irmão, "pregava no caixote duas rodas de lata de goiabada, "a gente ia viajar", isto é, "imitava estar viajando" de carro, "puxado por dois bois", numa tarde em que "as cigarras derretiam ... com seus cantos", rumo à cidade porque o irmão tinha uma namorada, "isso ele contava”, mas na travessia de "um rio inventado", "o carro afundou e os bois morreram afogados", porém chegavam sempre "no fim do quintal".

Com ilustrações de João Caetano, A maior flor do mundo narra a estória de um escritor (a ilustração mostra o próprio Saramago) que alimenta o desejo de escrever para crianças, porém não se considera apto, pois "faz falta um certo jeito de contar". Mesmo assim, arrisca a contar "uma linda história que um dia inventei", que se passa numa "aldeia" onde mora o "herói menino" que sai em busca de aventura (a ilustração mostra Saramago criança). Embalado pelo "tempo alto, largo e profundo da infância”, sai o menino como pintassilgo, de árvore em árvore, desce rio, vai a Marte, corta campos, bosques, "andou, andou" até chegar a uma colina onde está uma flor "tão caída, tão murcha" que ele resolveu salvá-la, indo ao rio Nilo, pegando gotas d'água, em "cem mil viagens". A flor recuperada, do tamanho de um carvalho, perfuma o ar e deita sombra onde o menino dorme.

Preocupados, a família e os vizinhos procuram-no, até encontrálo, coberto por "uma grande pétala, perfumada, com todas as cores do arco-íris”, cuja ilustração mostra ser um mapa ${ }^{7}$. Levado para casa, é 
recebido com respeito "como obra de milagre" e, quando passava pelas ruas, "as pessoas diziam que ele saíra da aldeia para ir fazer uma coisa que era muito maior do que o seu tamanho e do que todos os tamanhos”. Ao final, a ilustração mostra novamente Saramago (adulto) a dizer: "este era o conto que eu queria contar", numa retomada ao início da narrativa em que o desejo do escritor é o mote para o enredo.

Tanto em Manoel de Barros como em José Saramago, temos explícita a evocação da infância como um estado de percepção da realidade pelos sentidos que, por sua vez, possibilita atravessar o universo da linguagem, tecendo literariedade - característica constituída a partir do trabalho estético dos autores, a ser complementado pelos leitores num exercício de leitura crítica, configurando, pois, a noção de obra aberta, segundo Umberto Eco ${ }^{8}$ que afirma ser o texto "uma máquina preguiçosa pedindo ao leitor que faça uma parte de seu trabalho".

Ambos os autores combinam imagens relacionadas ao pensamento mágico, em ações situadas no âmbito do maravilhoso, comunicando uma realidade através de comparações, símbolos, alegorias, mostrando que literatura é "a linguagem da representação, linguagem imagística que, como nenhuma outra, tem o poder de concretizar o abstrato"9, criando um universo lúdico, ao mesmo tempo em que veicula elementos questionadores sobre o mundo e sobre o próprio homem. Tais recursos conferem às obras unidade semântica com propriedades formais caracterizadas semioticamente, com destaque para a expressividade. ${ }^{10}$

possivel inferir as palavras Portugal, África, Portalegre. Outra ilustração mostra os mapas da Europa, África e América do Sul, tendo ao lado a flor, constituindo-se uma referência tanto aos países da Comunidade dos Países de Língua Portuguesa (CPLP), como aos três continentes onde o português é falado.

8 ECO, Umberto. Sete Passeios pelos Bosques da Ficção. Tradução de Hildegard Feist. São Paulo, Companhia das Letras, 1999, p. 9.

9 COELHO, Nelly Novaes. Literatura Infantil: teoria, análise, didática. São Paulo, Ática, 1993, p.38.

10 SILVA, Vitor Manoel Aguiar e. Teoria da Literatura. Coimbra, Livraria Almedina, 1984, pp.574-575. 
É possível perceber que os autores rompem os limites do uso trivial da linguagem, para atingir o inusitado, explorando o espaço da palavra, essa manifestação do indivíduo, viva, dinâmica, reveladora do mundo objetivo e subjetivo, sem, no entanto, deixar de tangenciar a experiência do leitor ou de referir-se a um estar no mundo. É aquilo que Regina Zilberman nomeia de natureza iluminista da obra de arte, aí incluída a literatura, no interior da qual jaz "uma ânsia de liberação e a esperança de um vir-a-ser mais humanizado" ${ }^{11}$, função essa que fica evidente na afirmação do teórico Antonio Cândido: "A literatura desenvolve em nós a quota de humanidade na medida em que nos torna mais compreensivos e abertos para a natureza, a sociedade, o semelhante" 12 .

Em Exercícios de ser Criança e em A maior flor do mundo, somos convidados a pensar na função metalingüística da linguagem, enquanto objeto que olha e ao mesmo tempo é olhado, isto é, trata-se de uma atividade lingüística em que a própria linguagem está em jogo, através de um trabalho de extenuação como explica Roland Barthes: "Trata-se de fazer aparecer, por transmutação (e já não apenas por transformação), um novo estado filosofal da matéria da linguagem; esse estado inaudito, esse metal incandescente, fora da origem...."13.

Os textos literários detêm uma materialidade que põem em relevo, simultaneamente, riqueza de forma, de conteúdo, inventividade e polissemia, portanto aproxima os dois autores a travessia pela linguagem numa relação de encantamento que resulta num fecundo campo fictício e poético, contudo em José Saramago, mais do que em Manoel de Barros, sem que esse fato engrandeça ou diminua a obra de um perante a obra do outro, é possível verificar, para além do arrebatamento, uma explicitação mais enfática do papel da língua literária, no caso em Língua Portuguesa, como instrumento

11 ZILBERMAN, Regina. "A Literatura Infantil e o Leitor”. IN: ZILBERMAN, Regina e MAGALHÃES, Ligia Cademartori. Literatura Infantil: autoritarismo e emancipação. São Paulo, Ática, 1987, p.78.

12 CANDIDO, Antonio. A Educação pela Noite. Rio de Janeiro, Ouro sobre Azul, 2006.

13 BARTHES, Roland. O prazer do texto. Lisboa, Edições 70, 1973, p. 71. 
indispensável para fazer frente ao processo de mundialização que desconsidera nossas diferenças.

O certo é que lendo as duas obras, migra-se do real para o imaginário, fazendo-se reconhecer o texto literário como "um autêntico e complexo exercício de vida, que se realiza com e na Linguagem - esta complexa forma pela qual o pensar se exterioriza e entra em comunicação com os outros pensares" ${ }^{14}$, sendo nessa materialidade de visões múltiplas que reside o valor imensurável da leitura literária enquanto ação crítica, efetiva, afetiva, de modo a garantir conhecimento, reflexão, discernimento, amadurecimento e transformação. Pelo exposto, os textos ora analisados possibilitam ao leitor uma travessia instigante pela palavra, ao mesmo tempo em que desenvolve a sensibilidade estética, suscita emoção, promove o prazer, funções inerentes ao texto literário como explica Bragatto Filho ${ }^{15}$.

Enquanto o menino na estória de Manoel de Barros, "com o tempo descobriu que escrever seria o mesmo que carregar água na peneira”, razão por que faria isso a vida toda, o menino na estória, de José Saramago, ao empreender tamanha aventura, rumo ao desconhecido para regar a flor - símbolo que representa a Língua Portuguesa - fez "uma coisa que era muito maior do que o seu tamanho e do que todos os tamanhos." Isso reflete a lúcida consciência social que ambos possuem acerca do papel do escritor em sua relação com a língua, bem como do seu caráter político, ideológico e cultural.

As frases "fazer peraltagens com as palavras", em Manoel de Barros e "Quem sabe se um dia virei a ler outra vez esta história, escrita por ti que me lês, mas muito mais bonita?...", em Saramago, revelam a expectativa que ambos possuem de o leitor de suas obras vir a desempenhar papel ativo no processo de criação e circulação literária, não em relações de influência ou de dependência cultural, mas sim de releituras criativas enquanto sujeito da própria história de leitura.

${ }_{14}$ COELHO, Nelly Novaes. Literatura: arte, conhecimento e vida. São Paulo, Peiropólis, 2000, p.24.

15 BRAGATTO FILHO, Paulo. Pela leitura literária na escola de $1^{\circ}$ Grau. São Paulo, Ática, 1995, p. 14. 
Assim é que a travessia pela palavra - matéria-prima da arte literária -, levada a efeito pelos escritores, constitui-se um exercício poético compromissado com um modo de dizer a realidade do mundo e do homem, do Brasil e de Portugal, fato que comprova ser híbrida a natureza da literatura, isto é, individual e social ao mesmo tempo ${ }^{16}$. Portanto, pela articulação da imaginação e do real, em suas criações literárias, Manoel de Barros e José Saramago buscam o olhar amoroso, o pensamento lúdico, a busca aventureira da infância, possibilitando ao leitor de todas as idades reflexões sobre si mesmo e sobre o outro.

Pelo exposto, ambos desempenham papel similar ao do intelectual que na análise de Said ${ }^{17}$ é um indivíduo com capacidade de pensamento e discernimento para representar o melhor pensamento, "a própria cultura", de tal forma que a comunidade nacional sinta, em grau elevado, uma identidade comum.

Importante ressaltar que as duas obras, catalogadas como Literatura infanto-juvenil, o que implica um destinatário - a criança ou jovem -, primam pela qualidade estética e polissêmica como é de se esperar de autores comprometidos com a formação humanística de gerações de leitores de seus países.

Em razão disso, apresenta-se fértil e promissora a linha do estudo comparativo das literaturas dos países de Língua Portuguesa, para relevar nosso comunitarismo cultural, tendo a modernidade como estratégia discursiva que permite atualização de um vir a ser histórico, situado, realçando nossas diferenças e incorporando a teoria à práxis, para desenvolver mais e mais articulações de caráter comunitário ${ }^{18}$.

Entretanto, é preciso ficar claro que não cabem análises para caracterizar literatura tal como paradigmática ou como dependente, uma vez que,

\footnotetext{
${ }^{16}$ COELHO, p. 26.

17 Op. Cit. p. 41.

18ABDALA JÚNIOR, Benjamin. "Algumas observações sobre a comparação entre escritores engajados das Literaturas de Língua Portuguesa", em De vôos e ilhas: Literatura e Comunitarismos. São Paulo, Ateliê Editorial, 2003.
} 
O campo magnético das literaturas vernáculas situa-se como resultante da atividade de várias estrelas que possuem um brilho diferente - existem estrelas mais novas ou mais velhas. A dinâmica do campo literário depende dessas diferenças de matizes que também se relacionam com as diferenças de matérias de cada uma delas e que servem de referência literárias ${ }^{19}$.

As obras não deixam dúvidas sobre a vitalidade ficcional e poética de Manoel de Barros e José Saramago como expressão concreta das possibilidades estéticas de trabalho com a mesma língua. Eles representam o sistema literário de diferentes países, porém, une os dois um profundo respeito pelo idioma português. Cabe, portanto, a nós, professores de literatura, juntarmo-nos a eles, pelo desempenho do papel de leitores críticos e criativos, para mediar o encontro de crianças e jovens com a obra literária. Boa literatura em português não falta.

\section{Referências bibliográficas}

ABDALA JÚNIOR, Benjamin. "Algumas observações sobre a comparação entre escritores engajados das Literaturas de Língua Portuguesa”, em De vôos e ilhas: Literatura e Comunitarismos. São Paulo, Ateliê Editorial, 2003.

BARROS, Manoel de. Exercícios de ser Criança. Bordados de Antônia Zulma et.alli. sobre desenhos de Demóstenes Vargas. Rio de Janeiro, Salamandra, 1999.

BARTHES, Roland. O prazer do texto. Lisboa, Edições 70, 1973.

BRAGATTO FILHO, Paulo. Pela leitura literária na escola de $1^{\circ}$ Grau. São Paulo, Ática, 1995.

CANDIDO, Antonio. A Educação pela Noite. Rio de Janeiro, Ouro sobre Azul, 2006.

COELHO, Nelly Novaes. Literatura Infantil: teoria, análise, didática. São Paulo, Ática.

Literatura: arte, conhecimento e vida. São Paulo, Peirópolis, 2000.

DURAS, Marguerite. Escrever. Tradução de Rubens Figueiredo, Rio de Janeiro, Rocco, 1994.

ECO, Umberto. Sete Passeios pelos Bosques da Ficção. Tradução de Hildegard Feist. São Paulo, Companhia das Letras, 1999.

LOURENÇO, Eduardo. "Da Filosofia como Literatura". IN: Estudos universitários de língua e literatura. Textos de vários autores. Rio de Janeiro, Editora Tempo Brasileiro, 1993.

SAID, Edward W. Representações do intelectual: As Conferências Reith de 1993. Tradução de Milton Hatoum, São Paulo, Companhia das Letras, s.d.

19 Idem, p. 115. 
SARAMAGO, José. A maior flor do mundo. Ilustrações de João Caetano. São Paulo, Companhia das Letrinhas, 2001.

SILVA, Vitor Manuel de Aguiar e. Teoria da Literatura. Coimbra, Livraria Almedina, 1984, pp. 574-575.

ZILBERMAN, Regina. “A Literatura Infantil e o Leitor”. IN: ZILBERMAN, Regina e MAGALHÃES, Ligia Cademartori. Literatura Infantil: autoritarismo $e$ emancipação. São Paulo, Ática. 